DOI 10.37882/2223-2974.2020.10.41

\title{
ОСОБЕННОСТИ ДОКАЗЫВАНИЯ В СПОРАХ О ПРАВАХ НЕСОВЕРШЕННОЛЕТНЕГО НА ЖИЛОЕ ПОМЕЩЕНИЕ
}

\section{FEATURES OF PROOF IN DISPUTES ABOUT THE RIGHTS OF A MINOR TO RESIDENTIAL PREMISES}

\section{Tsurik}

Summary: The child is the bearer of various rights and obligations, both personal and property, as a special subject of law. Chapter 11 of the Family code of the Russian Federation provides for the basic rights of minors, among which a special place is taken by property rights. The child, being the owner of property, also owns it as a family member, since the presence of a family-legal relationship is the basis for the right to property, namely, the fact of the child's descent from parents, established in a voluntary or judicial order, and the existence of a marriage between the child's parents. The child has a special position in the implementation of the relevant norms in practice, so it is necessary to take into account the characteristics of the subject itself, which is the bearer of the rights and obligations under discussion, as well as the legal nature of the relationship involving the child.

Keywords: evidence, housing, residential premises, limited property rights, guardianship, guardianship, property rights of a minor, representatives, etc.
Ж илье - один из важных элементов в жизни каждого человека, но не каждый гражданин, а тем более несовершеннолетний член нашего общества, несмотря на гарантии, закрепленные в ст. 40 Конституции РФ, может реализовать свое право на жилье. Наличие жилья включается в понятие достойного человека жизненного уровня.

Жилищные споры - особая разновидность споров, это конфликтные ситуации, возникающие в процессе эксплуатации жилого фонда при несоблюдении установленных нормативов собственниками, нанимателями и арендаторами жилых и нежилых помещений в жилых домах.

В связи с вышеизложенным представляет интерес исследование жилищных споров с участием несовершеннолетних, в том числе и их процессуальной стороны.

При совершении сделки с объектом жилой недвижимости важно не только подготовить договор, но и оценить законность объекта сделки, поскольку наличие среди собственников или лиц, имеющих право пользования объектом недвижимости, несовершеннолетнего,
Цурик Ирина Олеговна

Российский Государственный Университет Правосудия

(2. Хабаровск)

irina.tsurik@mail.ru

Аннотация: Несовершеннолетний является носителем различных прав и обязанностей как личного, так и имущественного характера как особый субъект права. Главой 11 Семейного кодекса Российской Федерации (далее(К РФ) предусмотрены основные права несовершеннолетних, среди которых особое место занимают имущественные права. Несовершеннолетний, являясь собственником имущества, также и владеет им как член семьи, так как наличие семейно-правовой связи является основанием возникновения права на собственность, а именно наличие факта происхождения ребенка от родителей, установленный в добровольном или судебном порядке, и существование брака между родителями ребенка (п. 3 ст. 60 СК РФ) [5]. Несовершеннолетнему свойственно особое положение в ходе реализации соответствующих норм на практике, в связи с чем необходимо учитывать особенности самого субъекта, являющегося носителем обсуждаемых прав и обязанностей, а также правовую природу отношений с участием ребенка.

Ключевые слова: доказательства, жилище, жилое помещение, ограниченные вещные права, опека, попечительство, право собственности несовершеннолетнего, представители и др.

чрезмерно усложняет процедуру отчуждения объекта. Без реализации права несовершеннолетнего на жилье, гарантированного ст. 40 Конституции РФ, участие его в отношениях собственности невозможно.

Тем не менее, жилищная проблема остается актуальной для большинства граждан нашей страны. Жилье остаётся ценностью для каждого человека, в том числе и для ребенка, как обладателя субъективного права на жилую площадь. На практике данное право реализуется сложно, ввиду отсутствия доступного жилья для большей части населения, несмотря на то, что оно относится к числу декларативных прав.

Целью нашей статьи является раскрытие процессуальных особенностей доказывания в спорах о правах несовершеннолетнего на жилое помещение.

Особенностям процессуального рассмотрения дел данной категории уделялось внимание в исследованиях таких ученых, как Черкашина И., Шиловская А.Л., Невинная И. и др.

Внедрение «ювенальной юстиции» в России осущест- 
вляется в основном по канадским моделям и ориентируется на документы ООН. Эта работа не сводится только к созданию уголовных судов для несовершеннолетних, а имеет целью решать более широкую задачу - создание ювенальных гражданских судов, особой системы исполнения наказания в отношении несовершеннолетних, решение социальных вопросов, связанных с несовершеннолетними, лишенными родительского попечения, в том числе и в случаях лишения родителей родительских прав, предусматривает широкие полномочия социальным службам, которые по существу будут контролировать родителей и исполнение ими родительских обязанностей, в том числе и по обращениям самих детей. По законопроекту были подготовлены заключения и отзывы более чем 40 организациями, в том числе Минюста, МВД РФ, Минобразования РФ, ведущих научных организаций, организаций, работающих с несовершеннолетними. Анализ отзывов не позволяет сделать выводы о существовании в российском обществе доминирующей концепции ювенальной юстиции.

Согласно отчёту Минстроя России «Развитие рынков ипотеки и жилищного строительства на 2000-2017» 45\% семей хотят улучшить жилищные условия - на это потребуется 1,4 млрд М2 жилья; половина семей хотела бы улучшить жилищные условия по причине недостатка площади, для чего потребуется примерно 17 лет при существующих темпах строительства [15]. Применение положений Жилищного кодекса РФ, принятого в 2004 году, и иных нормативно-правовых актов на практике оказалось непростым, в том числе и в отношении детей, являющихся собственниками жилых помещений. Несовершеннолетний, являясь собственником жилого помещения не может совершать самостоятельно какие -либо действия в отношении данного имущества без участия законных представителей, в этом и состоит сложность правового регулирования жилищных отношений с его участием. Проживание несовершеннолетнего в семье означает наличие у него статуса «член семьи», в чём и выражается особенность реализации прав ребенка на жилое помещение. Как показывает практика, не всегда соблюдается принцип равноправия членов семьи, нередко грубо нарушаются жилищные права детей их законными представителями. Многообразие оснований возникновения прав несовершеннолетнего на жилплощадь влечет различия в правовом положении (собственник жилого помещения, член семьи собственника или нанимателя, и т.д.)

Но существуют и некоторые особенности рассмотрения гражданских дел, связанных с правых граждан на жилье. Не смотря на многообразие жилищных споров, можно обозначить общие подходы, позволяющие избежать ошибок при их решении.

Проанализировав жилищное законодательство, основные доктринальные источники, судебную практику, мы можем выводить основные признаки жилищных споров, которые рассматриваются судами общей юрисдикции.

Во-первых, предметом жилищных споров является то или иное право на жилое помещение, и именно по предмету данная категория дел отличается от других гражданско-правовых споров.

Во-вторых, основания возникновения жилищных споров перечислены в соответствующих нормах, регулирующих те или иные жилищные правоотношения.

Итак, все жилищные споры, подлежащие рассмотрению в суде, в зависимости от правовых оснований возникновения можно разделить на следующие:

1. возникают из Жилищного кодекса РФ;

2. возникают из права собственности граждан на жилой дом (квартиру);

3. связанные с защитой права частной собственности гражданина;

4. возникают из жилищно-коммунальных отношений.

Таким образом, мы можем говорить о сужении круга жилищных споров, которые подведомственны судам общей юрисдикции.

Bсе споры рассматриваются по месту нахождения жилого помещения. То есть подсудность данной категории дел всегда является исключительной - по местонахождению жилья.

Определяя особенности рассмотрения жилищных споров, мы, прежде всего, обратим внимание на субъектный состав таких споров.

Особенность субъектного состава споров, возникающих из жилищных правоотношений обусловила возникновение и определенных процессуальных особенностей при рассмотрении данной категории дел. Государством дополнительно гарантируется охрана государственных, общественных интересов, прав и охраняемых законом интересов отдельных граждан путем участия в судебном производстве органов и лиц, которым законом предоставлено право защищать права, свободы и интересы других лиц. Решение вопроса о составе лиц, которые будут участвовать в деле, зависит от правильной квалификации правоотношений. При разрешении жилищных споров судами не всегда дается правильное определение процессуального положения участников по делу.

Чаще всего возникают ошибки, когда фактические соответчики привлекаются к участию в деле в качестве третьих лиц (в частности, по делам, которые связаны с обменом жилой площади), или когда не один соответчик вообще не вовлечен в дело. При этом, если в первом случае ограничения прав участника процесса усматри- 
вается в объеме его полномочий, которыми он обладает в процессе, то второе названное нарушение более серьезное - гражданин вообще лишен всякой возможности влиять на судебное разбирательство, поскольку он даже не стал его участником.

При рассмотрении жилищных споров с участием несовершеннолетних привлеченными могут и должны быть не только граждане, но и органы опеки, юридические лица. Ведь содержание понятия «жилищный орган» включает в себя любой орган, который осуществляет управление жилищным фондом, в том числе районные администрации, жилищно-эксплуатационные организации.

Однако привлечение необходимых лиц в большой степени связывается с несовершенством отечественного законодательства. Например, в случае износа дома лицу, которое будет выселено, предоставляется другое жилое помещение предприятием, учреждением, организацией - собственником дома, или местной администрацией. Действующее законодательство не содержит прямого ответа на вопрос о том, кто может обращаться в данном случае с заявлением о выселении в суд.

Еще одной отличительной чертой данной категории дел по сравнению с другими является предмет доказывания, который имеет свои особенности. Поскольку предметом исковых требований, как правило, является признание права на жилье либо выселение из него, то в предмет доказывания входит законность вселения и фактическое проживание в спорном жилом помещении, условия пользования им, а также смена нанимателем места жительства, то есть фактическое выбытие из жилого помещения.

Процессуальная особенность рассмотрения жилищных споров в суде заключается в способах доказывания фактов, подтверждающих правовую позицию по делу. Особенность заключается в том, что по данной категории дел существует приоритет показаний свидетелей над письменными доказательствами (документами). При рассмотрении любого жилищного спора привлекаются свидетели (как правило, истцом). Это связано с тем, что некоторые факты и обстоятельства, которыми стороны обосновывают свои требования и возражения, могут подтверждаться только показаниями свидетелей, поскольку другие средства доказывания не будут иметь никакого значения для дела. Например, при подаче иска о признании лица утратившим право на жилую площадь факт не проживания ответчика на спорной жилой площади подтверждается показаниями соседей. Констатация очевидного нарушения гражданином правил снятия и постановки на регистрационный учет по месту его преимущественного пребывания не означает, что суд признает его выбытие как факт расторжения им догово- ра найма. Отсутствие или наличие заключенного брака не является основанием признания или непризнания лица членом семьи.

Законом чётко определены категории лиц, такие как дети, родители и супруг, обладающие постоянным статусом члена семьи собственника жилого помещения [2]. Указанные в п. 1 ст. 31 ЖК РФ иные лица, могут быть признаны членами семьи собственника при наличии определенных обстоятельств, тем самым статус их будет считаться приобретенным. Они наделены одинаковым объёмом прав и обязанностей по отношению к принадлежащему собственнику жилому помещению, причём вне зависимости от основания возникновения такого статуса. Если иное не установлено соглашением между собственником и членами его семьи, то жилым помещением имеют право пользоваться члены семьи наравне с собственником, что распространяется и несовершеннолетних (п. 2 ст. 31 ЖК РФ). При этом правомочием распоряжения ребенок собственника не обладает, то есть правом собственности на имущество своих родителей не обладает (п. 4 ст. 60 СК РФ). Здесь стоит определить природу права несовершеннолетнего на жилое помещение, а это поспособствует выявлению способов защиты данного права. Находясь в статусе членов семьи собственника, их право пользования жилым помещение является бессрочным, и оно же возникает по умолчанию при вселении с собственником в жилое помещение (п. 2 ст. 31 ЖК РФ). Права членов семьи, как вещные права, подлежат абсолютной защите от различных посягательств в том числе и со стороны собственника. Прекращение права пользования членами семьи собственника следует за сменой собственника жилого помещения, а значит и несовершеннолетний, проживающий в данном жилом помещении теряет это право, если иное не предусмотрено соглашением между ними. Подобное положение предусмотрено в правовых последствиях отчуждения имущества, что следует из содержания положений жилищного законодательства (п. 4 ст. 31 ЖК РФ) и из норм гражданско-правового характера (п. 4 ст. 292 ГК РФ).

Члены семьи собственника, либо оставшиеся без родительского попечения несовершеннолетние члены семьи собственника, могут отчуждать жилое помещение с согласия органа опеки и попечительства, если при этом затрагиваются права и охраняемые законом интересы указанных лиц (Федеральный закон от 24.04.2008 N 48Ф3 (ред. от 01.03.2020) «Об опеке и попечительстве») [3]. И в этой связи, усматривается необходимость в более требовательном подходе к содержанию заключения органа опеки и попечительства. Чтобы дать указанное согласие органы опеки и попечительства должны быть осведомлены о соответствующем статусе несовершеннолетнего (п. 4 ст. 292 ГК РФ). Из этого следует, что согласие органов опеки и попечительства не требуется если им неизвестно о статусе несовершеннолетнего члена 
семьи собственника. То есть о предстоящей сделке органы опеки и попечительства должны быть проинформированы, что зачастую на практике не происходит. Неполучение разрешения органа опеки и попечительства членами семьи собственника при отчуждении жилого помещения влекут обращение данного органа в суд с иском о признании такой сделки недействительной. Предполагается, что жилищные права иной категории детей, не указанной в данном законе, подлежат защите их законными представителями(родителями) (п. 1 ст. 56 СК РФ). Иногда приходиться сталкиваться с многочисленными случаями нарушения жилищных прав детей как оставшихся без попечения родителей, так и находящихся под опекой и попечительством.

По всей видимости право пользования несовершеннолетним жилым помещением должно сохраняться даже при отчуждении этого помещения по договору купли-продажи, защищая интересы ребенка и его имущественные права. В законе же предусмотрено иное положение: «Переход права собственности на жилой дом или квартиру к другому лицу является основанием для прекращения права пользования жилым помещением членами семьи прежнего собственника, если иное не установлено законом. Члены семьи собственника жилого помещения могут требовать устранения нарушений их прав на жилое помещение от любых лиц, включая собственника помещения» (п. 2-3 ст. 292 ГК РФ) [4]. Данное положение указывает на то, что ребёнок прежнего собственника утрачивает право пользования жилым помещением. Из закона следует, что новый собственник может не возражать против сохранения прав третьих лиц на приобретенное по возмездной сделке имущество, что очень редко встречается на практике.

Пример из судебной практики. Истец при обращении в суд указала, что является собственником квартиры, в которой зарегистрированы ответчики - бывшая жена родного брата с двумя несовершеннолетними детьми. Удовлетворяя иск, суд первой инстанции сослался на положения ст. ст. 209, 288, 292 ГК РФ; ст. ст. 30, 31, 35 ЖК РФ и исходил из того, что ответчики не являются членами семьи нового собственника спорного жилого помещения, отец несовершеннолетних прекратил право пользования этим жилым помещением и снялся с регистрационного учета, регистрация ответчиков нарушает права истца на реализацию правомочий собственника квартиры. Отменяя указанное решение и принимая новое - об отказе в удовлетворении иска, суд апелляционной инстанции признал, что судом первой инстанции неправильно применены нормы материального права. Суд второй инстанции установил, что отец несовершеннолетних ответчиков после расторжения брака с их матерью подарил принадлежавшую ему на праве собственности квартиру (по адресу данной квартиры с рождения проживали и были зарегистрированы его дети) своему отцу, а тот, в свою очередь, передал квартиру в дар дочери, которая впоследствии и обратилась в суд с иском о выселении несовершеннолетних племянников. Сославшись на положения ст. 10 ГК РФ, ст. ст. 17, 38, 40 Конституции РФ, нормы ст. ст. 55 и 63 СК РФ, правовые позиции российских судебных органов, Конвенцию ООН о правах ребенка, суд второй инстанции пришел к выводу о злоупотреблении со стороны отца несовершеннолетних ответчиков и его близких родственников своими правами. Отчуждая жилое помещение, отец несовершеннолетних не предпринял никаких действий по обеспечению их другим жильем. Как видно из установленных судом фактических обстоятельств дела, действия отца несовершеннолетних детей и его близких родственников по передаче друг другу в короткий промежуток времени права собственности на спорную квартиру осуществлялись исключительно для того, чтобы прекратить право пользования жилым помещением несовершеннолетних детей [9].

В жилищном кодексе РФ статус ребенка как члена семьи более конкретизирован по сравнению с Семейным кодексом РФ, так как понятие «член семьи» составляет содержание значительного числа норм законодательства. В п. 11 «а» Постановления Пленума Верховного Суда содержится указание на то, кто и при каких условиях может обладать статусом «член семьи» собственника, согласно которому, ими являются проживающие совместно с ним в принадлежащем ему жилом помещении его супруг, а также его дети и родители [8]. Лица считаются супругами, если их брак заключен в органах записи актов гражданского состояния. Права и обязанности супругов возникают со дня государственной регистрации заключения брака в органах записи актов гражданского состояния (ст. 10 СК РФ). Факта совместного проживания членов семьи с собственником жилого помещения достаточно для подтверждения статуса «член семьи», и установления иных фактов не требуется, таких как ведение общего хозяйства, оказания материальной помощи и т.д. Статус «член семьи» в соответствии с п. 1 ст. 31 ЖК РФ определяется состоянием в браке и кровным родством, и является установленным, но не самостоятельным, так как зависит от воли собственника жилого помещения.

В процессе судебного разбирательства в указанных спорах учитывается цель вселения собственником того или иного лица. В связи с чем, суд выстраивает доказательственную базу, состоящую из объяснений сторон, третьих лиц, показаний свидетелей, письменных документов (например, договор найма) и иных доказательств (ст. 55 ГПК РФ), п. 11 «б» Постановления Пленума Верховного Суда РФ от 02.07.2009 N 148 [16].

При наличии статуса «бывший член семьи»у несовершеннолетнего, по закону и по совести его защита 
зависит напрямую от воли собственника жилого помещения, а это может привести к тому, что фактически несовершеннолетнему «некуда будет пойти», а защитить самостоятельно свои права он не сможет в отсутствии законных представителей, и поэтому без участия соответствующих органов, защищающих интересы несовершеннолетнего, невозможен эффективный механизм исполнения закона, касающегося данной сферы [10]. Длящийся характер жилищных отношений влечет применение к ним того закона, который действует в настоящее время, без учёта времени прекращения семейных отношений [6].

Критерии самостоятельности статуса несовершеннолетнего как члена семьи собственника точно не определены, исходя из анализа ст. 31 ЖК РФ, что означает формальный подход к самостоятельности субъекта при реализации жилищных прав. В связи с чем, особенности указанного статуса несовершеннолетнего должны учитываться в нормах жилищного законодательства. Сделки, совершаемые с участием несовершеннолетних в статусе членов семьи должны совершаться под неусыпным контролем органов опеки и попечительства, а также органов, осуществляющих регистрационные функции [2].

В заключении стоит отметить, что правовой статус ребенка в процессуальном доказывании, как понятие, требует однозначного определения, и чёткого разграничения жилищно-правовой и семейно-правовой сфер в данном контексте. Решение этой проблемы смогло бы привнести полезные дополнения в теорию права, и помогло в осуществлении единообразного подхода в судебной практике касаемо особенностей доказывания в спорах об ограничении вещных прав несовершеннолетних на жилые помещения. В ходе рассматриваемой темы были выявлены правовые проблемы, решение которых усовершенствовало бы законодательство и правоприменительную практику.

Мы можем говорить о том, что общие нормы гражданского процессуального права оказывают влияние на порядок рассмотрения жилищных споров с участием несовершеннолетних, но особенности рассмотрения споров, возникающих из жилищных правоотношений, определяют нормы, устанавливающие особенную подведомственность и подсудность, особый круг лиц, участвующих в деле, особенности средств доказывания и др., которые относятся к сфере гражданского процесса, несмотря на то, что они закреплены, в основном, в жилищном законодательстве. Считаем, что актуальной задачей для судов на ближайшее время будет становление правильной и непротиворечивой практики применения жилищного законодательства.

\section{ЛИТЕРАТУРА}

1. Конституция Российской Федерации» (принята всенародным голосованием 12.12.1993 с изменениями, одобренными в ходе общероссийского голосования 01.07.2020).

2. Жилищный кодекс Российской Федерации» от 29.12.2004 N 188- Ф3 (ред. от 06.02.2020).

3. Федеральный закон от 24.04.2008 N 48-Ф3 (ред. от 01.03.2020) «06 опеке и попечительстве».

4. Гражданский кодекс Российской Федерации (часть первая) от 30.11.1994 N 51-Ф3 (ред. от 16.12.2019).

5. Семейный кодекс Российской Федерации» от 29.12.1995 N 223-Ф3 (ред. от 06.02.2020).

6. Федеральный закон «0 введении в действие Жилищного кодекса Российской Федерации» от 29.12.2004 N 189-Ф3 (последняя редакция).

7. Федеральный закон «0 жилищных субсидиях гражданам, выезжающим из районов Крайнего Севера и приравненных к ним местностей» от 25.10 .2002 N 125-Ф3 (последняя редакция).

8. Постановление Пленума Верховного Суда РФ от 02.07.2009 N 14 «0 некоторых вопросах, возникших в судебной практике при применении Жилищного кодекса Российской Федерации» // Бюллетень Верховного Суда. 2009. N 9.

9. Шиловская А.Л. Проблемы защиты жилищных права несовершеннолетних // Гуманитарные, социально-экономические и общественные науки. - 2017.

10. Невинная И. Развод и детские метры // Российская газета. - 2005. - № 3.

11. Черкашина И. Судебная защита права пользования жилым помещением //Российская юстиция. 2004. N 5.

12. Тихомиров М.Ю. Защита прав на жилые помещения: практическое пособие / Тихомиров М. Ю. - М.: Изд. Тихомирова М. Ю., 2011. - 157 с.

13. Крутер К.А. Ограниченные вещные права на жилые помещения / К.А. Крутер; Иркутский институт (филиал) Всероссийского государственного университета юстиции (РПА Минюста России). - Иркутск: ВГУЮ (РПА Минюста России), 2018. - 195 с.

14. Право собственности и другие вещные права на жилые помещения / Чайкин Михаил. - М.: Лаборатория книги, 2010. - 120 с.

15. https://дом.рф/wp-content/uploads/2016/04/AHML_17-let_2017.12.11.pdf

16. 0 некоторых вопросах, возникших в судебной практике при применении Жилищного кодекса Российской Федерации // http://www.consultant.ru/ document/cons_doc_LAW_89120/

○ Цурик Ирина Олеговна (irina.tsurik@mail.ru). 